\title{
Association of Language Skills with Other Developmental Domains in Extremely, Very, and Moderately Preterm Children: EPIPAGE 2 Cohort Study
}

\author{
Marie-Laure Charkaluk, MD, $\mathrm{PhD}^{1,2,3,4}$, Jessica Rousseau, $\mathrm{MSc}^{1,2}$, Valérie Benhammou, $\mathrm{PhD}^{1,2}$, \\ Valérie Datin-Dorrière, $\mathrm{MD}^{2,5,6}$, Cyril Flamant, $\mathrm{MD}, \mathrm{PhD}^{7}$, Catherine Gire, $\mathrm{MD}^{8,9}$, Sophie Kern, $\mathrm{PhD}^{10}$, \\ Véronique Pierrat, $\mathrm{MD}, \mathrm{PhD}^{1,2,11}$, Monique Kaminski, $\mathrm{MSc}^{1,2}$, and Stéphane Marret, MD, $\mathrm{PhD}^{12,13}$
}

Objective To analyze language skills in children born at 24-34 weeks of gestation at 2 years of corrected age and the association between language and other developmental domains.

Study design We included 2424 children (64\% of the eligible population) from the French population-based EPIPAGE 2 cohort study. At 2 years' corrected age, children were screened with the French short version of the MacArthur-Bates Communication Developmental Inventories and the Ages and Stages Questionnaire completed by parents.

Results Small lexicon size, $<10$ th percentile of the calibration sample (ie, 28 words in a list of 100) was observed in 135 of 300 children (45\%) born at 23-26 weeks, 484 of $1513(32 \%)$ born at 27-31 weeks, and 165 of 611 (27\%) born at 32-34 weeks of gestation. Small lexicon size was associated with 2 other language measures: word combination use and the Ages and Stages Questionnaire communication domain score. It was also significantly associated with the Ages and Stages Questionnaire score below the threshold in the other developmental domains (gross motor function, fine motor function, problem solving skills, and personal social skills) for all gestational age groups, after adjustment for potential confounders. Overall, $46 \%$ of children with a small lexicon size had $\geq 1$ of these domains below the threshold, as compared with only $22 \%$ of children without a small lexicon size.

Conclusions These results highlight the usefulness of the MacArthur-Bates Communication Developmental Inventories in preterm children, especially those who do not participate in specialized follow-up. A small lexicon size points to developmental difficulties in language and increased risk for other developmental and neurobehavioral functions. (J Pediatr 2019; $\mathbf{\square}: 1-7$ ).

hildren born preterm are at risk of later developmental impairments and learning problems. Neurodevelopmental consequences of preterm birth are not limited to very preterm children, but are also found in moderately or late preterm children. ${ }^{1}$ Language function is one of the potentially affected areas, and language skills of preterm children have been the subject of many recent studies as well as 2 meta-analyses. ${ }^{2,3}$ Language skills are poorer for preterm than term children, with performances about -0.5 to $-1.0 \mathrm{SD}$ in each domain studied. ${ }^{2}$ These language difficulties seem to increase as language becomes more complex, from age 3 to 12 years. ${ }^{3}$ Poor communication skills have been identified in children as young as 12 months of age, born before 28 weeks of gestation. ${ }^{4}$ At $24-30$ months, $20 \%-30 \%$ of preterm children in different gestational age groups show language impairments or delays; 1 study found that $64 \%$ of extremely preterm children had a language delay at 30 months of corrected age. ${ }^{5,6}$ Late preterm children also exhibit communication impairments as early as 18 months of age and later. ${ }^{7}$

Language plays a particular role in learning abilities. Its achievement is built on a strong basis of nonverbal communication and requires a high level of sensory, perceptual, and fine motor skills. It is also needed for building both cognitive processes and social relations. Despite these considerations, in preterm children, language is rarely studied in terms of other aspects of development. In 1 study,

\footnotetext{
ASQ Ages and Stages Questionnaire

CDI Communication Development Inventories

EPIPAGE French EPldémiologie des Petits Ages GEstationnels
}

From the ${ }^{1}$ Obstetrical, Perinatal and Pediatric Epidemiology Research Team, Epidemiology and Biostatistics Sorbonne Paris Cité Research Center (U1153), INSERM, Paris; ${ }^{2}$ Paris Descartes University, Paris; ${ }^{3}$ Université Catholique de Lille, Lille; ${ }^{4}$ Service de néonatologie, Hôpital Saint Vincent de Paul, Groupement des Hôpitaux de l'Institut Catholique Lillois/Faculté de Médecine et Maïeutique, Lille; ${ }^{5} \mathrm{CHU}$ de Caen, Néonatologie-Réanimation, Avenue de la Côte de Nacre, Caen; ${ }^{6}$ Université Paris Descartes, CNRS UMR 8240 " Caen, '́n LaPsyDe ", Laboratoire A Binet, Sorbonne, 46 rue Sain Jacques, Paris, "Médecine neonatale, CHU de Nantes, Hôpital Mère Enfant, 38 boulevard Jean Monnet, Nantes
cedex; ${ }^{8} \mathrm{APHM}$, Néonatologie-Camsp, Marseille; ${ }^{9} \mathrm{AMU}$ Aix Marseille Université, EA 3279, Santé Publique et maladies chroniques, Qualité de vie, concepts, usages et limites, Déterminants, Faculté de médecine, Marseille; ${ }^{10}$ UMR 5596 (CNRS-Lyon2), Lyon; ${ }^{11} \mathrm{CHU}$ Lille, Department of Neonatal Medicine, Jeanne de Flandre Hospital, F-59000 Lille; ${ }^{12}$ Department of Neonatal Medicine, Neuropediatrics and Functional Education of the Child Rouen University Hospital, Rouen; and ${ }^{13}$ the Child Rouen University Hospital, Rouen; and neurological handicap and Neuroprotection IRIB, School of Medicine, Rouen University, Rouen, France Funded by the French Institute of Public Health Research/Institute of Public Health and its partners: the French Health Ministry, the National Institute of Health and Medical Research (INSERM), the National Institute of and Medical Research (INSERM), the National Institute of (CNSA); the National Research Agency through the French EQUIPEX program of investments in the future (reference ANR-11-EQPX-0038); the PREMUP Foundation; and the National Research Agency through the ANR program (reference ANR-13-APPR-0007-01-EPILANG). The funders had no role in the study design, data collection and analysis, decision to publish, or preparacollection and analysis, decision to publish, or prepara-
tion of the manuscript. The authors declare no conflicts of interest.

0022-3476/\$ - see front matter. ๑ 2019 Elsevier Inc. All rights reserved. https://doi.org/10.1016/.jpeds.2018.12.007 
mental and psychomotor scores on the Bayley Scales of Infant Development II were significantly reduced for extremely low birthweight children at 30 months of corrected age with language delay. ${ }^{6}$ However, precise knowledge of how language performance is related to other developmental aspects would be useful in better understanding determinants and implications of poor language skills in preterm children.

The aim of the present study was to analyze language skills at 2 years of corrected age in a large population-based cohort of preterm children, the French EPIdémiologie des Petits Ages GEstationnels (EPIPAGE) 2 cohort and to describe the interrelations of these skills as well as their relationship with competencies in motor, cognitive, and social domains of development in extremely, very, and moderately preterm children. Our a priori hypothesis was that language skills would be associated with competencies in other developmental domains, and the aim of the present study was to confirm and quantify these links.

\section{Methods}

EPIPAGE 2 is a prospective, national, population-based cohort of children born at 22-34 completed weeks of gestation in France in 2011. ${ }^{8}$ Children born at 22-26 weeks of gestation were recruited during an 8-month period, those born at 27-31 weeks of gestation during a 6-month period and those born at 32-34 weeks of gestation during a 5-week period. Only 1 region ( $2 \%$ of all births) did not participate. At recruitment, 5170 children born alive participated. At 2 years of corrected age, children underwent a detailed physical and neurologic examination by a physician, and the child's development was assessed by parental questionnaires. All families received information and agreed to participate in the study. The study was approved by the National Data Protection Authority (CNIL no. 911009) and the ethics committees (CCTIRS no. 10.626 and CPP SC-2873).

For the current study, we excluded children with congenital conditions associated with abnormal development, children with cerebral palsy identified at 2 years' corrected age, or children using equipment such as splints or orthotics in the absence of identified cerebral palsy, children with bilateral deafness or hearing equipment, and children with blindness (Figure). Only children for whom French was spoken at home, as the only language or in association with another language, were included. Questionnaires completed between 22 and 26 completed months of corrected age were retained for analysis.

\section{Language and Developmental Assessments}

The most commonly used parental questionnaires addressing early communication and language abilities are derived from the MacArthur-Bates Communicative Development Inventories (CDI). The short version of the French adaptation of the CDI was used. ${ }^{9}$ This questionnaire studies the development of lexicon and early grammar by measuring lexicon size and word combination use (yes/no). Lexicon size is the number of words the parents say their child use spontaneously, whatever the pronunciation, based on a list of 100 words. The 10th percentile of lexicon size is 28 words in the French calibration of the test conducted with 385 children; this threshold was used to define small lexicon size. Word combination was considered present if the child associated words sometimes or often. In the test calibration,

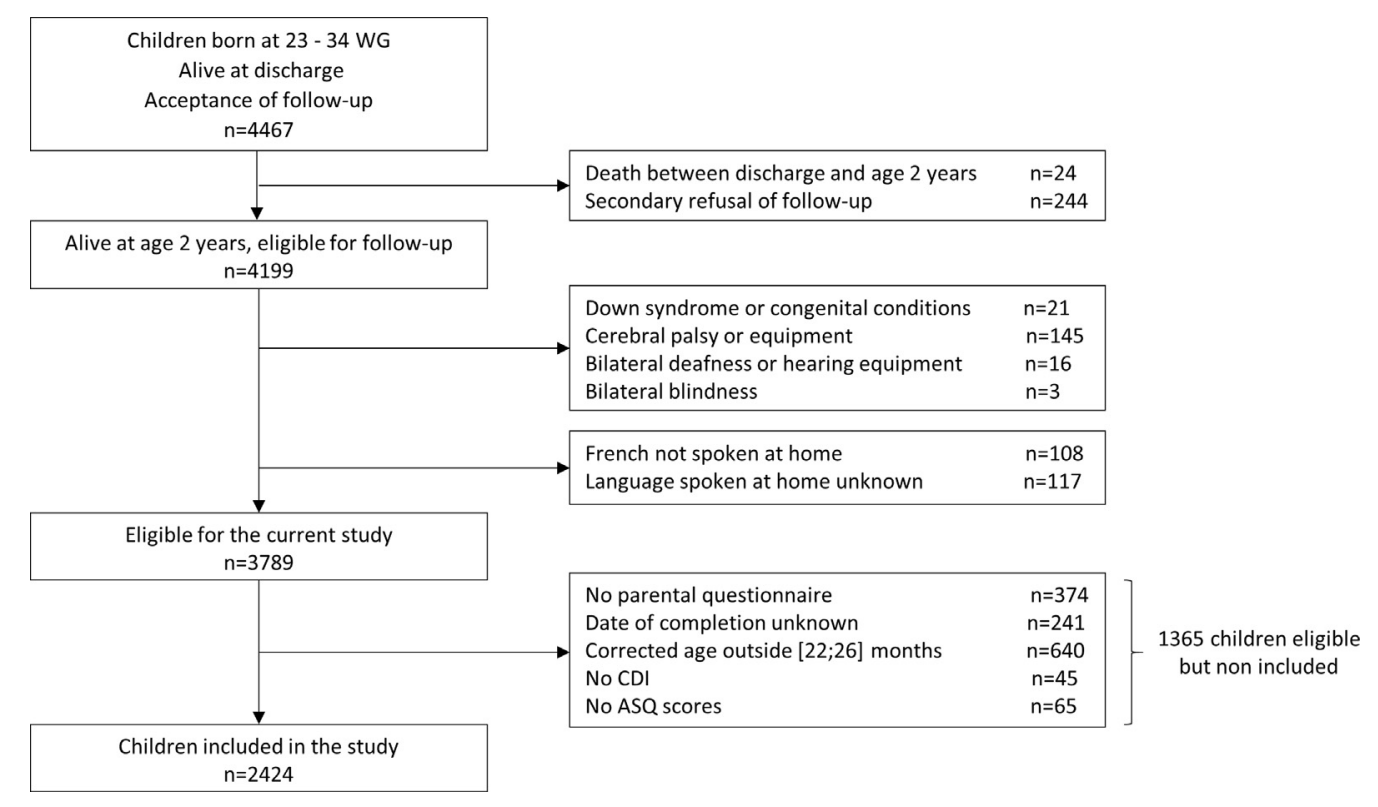

Figure. Study flowchart. 
$91 \%$ of children aged 24 months already combined words. The use of the CDI is promoted by the French Ministry of Health as a part of the routine assessment for all children, during follow-up by general practitioners or pediatricians (http://solidarites-sante.gouv.fr/IMG/pdf/05.ifdc-2.pdf).

The Ages and Stages Questionnaire (ASQ), 2nd version, is a brief parental questionnaire used to rate the child's current skills and development. ${ }^{10}$ Parents answer 6 questions in each of the 5 domains of development: communication, gross motor, fine motor, problem-solving, and personal-social skills. Parents are instructed to try activities with their child when necessary. The communication domain includes 2 items measuring receptive language skills and 4 measuring expressive language skills. Each question is scored 10, 5, or 0 according to parents' answers: yes, sometimes, or not yet, respectively. Scores for each domain are calculated by summing the score for the 6 questions. Missing answers are replaced by the mean of the answers for the other questions in the same domain, within the limit of 2 missing questions per domain. ${ }^{10}$ US norms are available for each domain, and thresholds corresponding with scores of $<2$ SD below the mean are available for each domain. The ASQ is not routinely used in primary care in France but can be part of the specialized follow-up existing in most regions for very preterm children. ${ }^{11}$ It has been validated in a French population of children born preterm. ${ }^{11}$

\section{Statistical Analyses}

Children included in the analysis were first compared with children eligible for the study but not included because of missing or partial questionnaires or questionnaires completed out of the 22-26 months corrected age window (Figure). Language skills (ie, lexicon size, word combination use) and ASQ communication domain scores, and their interrelations were described for the whole population and using 3 gestational age groups: 23-26, 27-31, and 32-34 weeks, referring to extremely, very, and moderately preterm, respectively. ${ }^{8}$ Multiple imputations were conducted to account for selective dropouts and missing information in the description of language skills at 2 years of corrected age, by chained equation with the SAS (SAS Institute Inc, Cary, North Carolina) multiple imputation procedure. Imputation model variables included those predicting nonresponse and/or those correlated with outcomes (Table I; available at www.jpeds. com). Thirty-six independent imputed datasets were generated. Estimates were pooled according to Rubin's rule and are presented with 95\% CIs.

The median ASQ scores, proportions of ASQ scores below the threshold in each domain except communication, proportion of children with $\geq 1$ ASQ domain below the threshold, and number of ASQ domains below the threshold were described among children with and without a small lexicon size. These relations were studied crude and after adjustment for potential confounders identified in the literature as being associated with language skills in early childhood. These confounders included sex, gestational age (completed weeks of gestation), growth restriction at birth (birthweight $<10$ th percentile according to Epopé curves ${ }^{12}$ ), maternal parity (primaparity vs multiparity), maternal educational level (some high school or less, high school diploma, some college, college diploma), and language spoken at home (French only vs French and other language). Similarities within twins or triplets sets were accounted for by use of a random intercept model with the GaussHermite method of estimation, a type of generalized linear mixed model demonstrated to be appropriate in samples including $>10 \%$ multiple births. ${ }^{13}$ These analyses were conducted for the entire population and for each gestational age group. Studies of the development of language in twins report that twins have higher rates of language delay than do singletons. ${ }^{14}$ For this reason, a sensitivity analysis restricted to singletons was also conducted. In all analyses, data were weighted to account for the different inclusion periods by gestational age. Analyses were conducted using SAS v9.4. A $P$ value of $<.05$ was considered statistically significant.

\section{Results}

Among the 4199 children eligible for follow-up at 2 years of corrected age, 3789 were eligible for the current study; 1255 questionnaires were missing or excluded, and 110 questionnaires were incomplete for the French CDI and/or ASQ (Figure). Thus, 2424 children were included in the study, representing $64 \%$ of the 3789 eligible children. Children not included had an older gestational age and were more often born from single pregnancies than the included children. Their mothers had a significantly lower educational level and were less often monolingual French (Table II). Among the 2424 children studied, 8\% were aged 22 months, $63 \%$ aged 23 or 24 months, and $29 \%$ aged 25 or 26 months.

Four words were spontaneously used by $>80 \%$ of the children: mummy (97\%), daddy (96\%), baby (84\%), and allo $(83 \%)$. For the whole preterm population, the median lexicon size was 48 (IQR, 24-78), and $29 \%$ had a small lexicon size. In all, $22 \%$ of the children did not use word combination. The median score for the ASQ communication domain was 48 (IQR, [28-55]). For $20 \%$ of the children, the score was below the threshold $(<-2 \mathrm{SD})$. For the 2 items addressing receptive language, $74 \%$ of children achieved the item "points to $\geq 1$ correct picture upon request" and $92 \%$ the item "carries out $\geq 3$ directions"; however, the 4 items addressing expressive language had lower achievement rates, between $29 \%$ and $64 \%$.

These language measures differed significantly between gestational age groups, with the worst performance in extremely preterm children $(P<.001$; Table III). Small lexicon size was observed in $45 \%, 32 \%$, and $27 \%$ of children born at 23-26, 27-31, and 32-34 weeks, respectively. Multiple imputation provided similar results (Table III). 


\begin{tabular}{|c|c|c|c|c|c|}
\hline & Children included $(n=2424)$ & Children excluded $(n=1365)$ & & & \\
\hline Children's characteristics & n (\%) & n (\%) & $\mathbf{O} \mathbf{R}^{\star}$ & $95 \% \mathrm{Cl}$ & $P$ value \\
\hline Gestational age (weeks) & & & & & $<.001$ \\
\hline $23-26$ & $300(4.5)$ & $146(3.5)$ & 0.9 & $0.7-1.1$ & \\
\hline $27-31$ & $1513(30.8)$ & $808(26.5)$ & 1 & & \\
\hline $32-34$ & $611(64.7)$ & $411(70.0)$ & 1.3 & $1.1-1.5$ & \\
\hline Small for gestational age & & & & & .38 \\
\hline No & $855(34.4)$ & $454(32.6)$ & 1 & & \\
\hline Yes & $1569(65.6)$ & $911(67.4)$ & 1.1 & $0.9-1.3$ & \\
\hline Sex & & & & & .99 \\
\hline Female & $1151(47.1)$ & $652(47.1)$ & 1 & & \\
\hline Male & $1273(52.9)$ & $713(52.9)$ & 1.0 & $0.8-1.2$ & \\
\hline Severe bronchopulmonary dysplasia & & & & & .01 \\
\hline No & $2281(97.5)$ & $1304(98.3)$ & 1 & & \\
\hline Yes & $143(2.5)$ & $61(1.7)$ & 0.7 & $0.5-0.9$ & \\
\hline Severe cerebral lesions & & & & & .85 \\
\hline No & $2185(97.8)$ & $1212(97.6)$ & 1 & & \\
\hline Yes & $80(2.2)$ & $52(2.4)$ & 1.0 & $0.7-1.7$ & \\
\hline Retinopathy of prematurity (stage 3 or higher) & & & & & .87 \\
\hline No & $2084(99.7)$ & $1150(99.7)$ & 1 & & \\
\hline Yes & $20(0.3)$ & $11(0.3)$ & 0.9 & $0.4-2.0$ & \\
\hline Necrotizing enterocolitis (stage 2-3) & & & & & .91 \\
\hline No & $2314(98.2)$ & $1301(98.2)$ & 1 & & \\
\hline Yes & $65(1.8)$ & $37(1.8)$ & 1.0 & $0.6-1.7$ & \\
\hline First child & & & & & .27 \\
\hline Yes & $1367(56.4)$ & $697(53.9)$ & 1 & & \\
\hline No & 1034 (43.6) & $652(46.1)$ & 1.1 & $0.9-1.3$ & \\
\hline Multiple pregnancy & & & & & .02 \\
\hline No & $1530(61.1)$ & $951(66.0)$ & 1 & & \\
\hline Yes & $894(38.9)$ & $414(34.0)$ & 0.8 & $0.7-1.0$ & \\
\hline Maternal educational level & & & & & $<.001$ \\
\hline Some high school or less & $615(24.0)$ & $558(40.1)$ & 2.6 & $2.0-3.3$ & \\
\hline High school diploma & $490(20.4)$ & $300(23.2)$ & 1.8 & $1.3-2.3$ & \\
\hline Some college & $528(22.8)$ & $198(15.4)$ & 1.0 & $0.8-1.4$ & \\
\hline College diploma & $752(32.8)$ & $258(21.3)$ & 1 & & \\
\hline Language spoken at home & & & & & $<.001$ \\
\hline French only & $1832(78.7)$ & $897(67.1)$ & 1 & & \\
\hline French + other language & $592(21.3)$ & $468(32.9)$ & 1.8 & $1.5-2.2$ & \\
\hline
\end{tabular}

Percentages and analyses are weighted to account for the different inclusion periods by gestational age.

Severe bronchopulmonary dysplasia defined as oxygen requirement at day 28 together with mechanical ventilation or continuous positive airway pressure or an Fi ${ }_{2}$ of $\geq 30 \%$ at 36 weeks' corrected age.

Severe cerebral lesions defined as grade III or IV intraventricular hemorrhage or cystic periventricular leukomalacia.

${ }^{*} \mathrm{OR}$ of not being included.

Among the 775 children with a small lexicon size, $73 \%$ also did not use word combinations and/or had an ASQ communication domain score below the threshold: $80 \%, 76 \%$, and $72 \%$ of extremely, very, or moderately preterm children, respectively. Among the 1618 children with a lexicon size of $\geq 10$ th percentile, $93 \%$ used word combination and had an ASQ communication domain score above the threshold: $88 \%, 92 \%$, and $93 \%$ of extremely, very, or moderately preterm, respectively (Table IV; available at www.jpeds.com).

Children with a small lexicon size had significantly more frequent ASQ scores below the threshold in any domain, before and after adjustment for potential confounders (Table V). These associations were found in extremely, very, and moderately preterm children. Apart from the communication domain, approximately half of the children with a small lexicon size showed $\geq 1$ other domain below the threshold. Conversely, $>75 \%$ of children without a small lexicon size showed no other domain below the threshold. The sensitivity analysis among singletons confirmed these findings (Table VI; available at www.jpeds.com).

\section{Discussion}

This French population-based cohort showed that a high percentage of preterm children had poor language skills at 2 years of corrected age. Lexicon size was highly associated with other measures of language skills and also with all other developmental functions in all gestational age categories of preterm infants at 2 years of corrected age.

Children's development was assessed using standard parental questionnaires. Data on the validity of parental assessments of their children's development are numerous and reassuring. ${ }^{15}$ The definition of a positive screen with the ASQ when $\geq 1$ domain is below the threshold has a sensitivity of 0.88 and specificity of 0.57 for identifying preterm children with a developmental quotient of $<85$. $^{11}$ A good correlation between parent-reported measures and professional assessment of language has been shown. ${ }^{16}$ MacArthur-Bates Inventories are considered a reliable measure of early expressive lexicon, and the short version has previously been used to describe expressive language in 
Table III. Language skills by gestational age

\begin{tabular}{|c|c|c|c|c|c|c|}
\hline \multirow[b]{4}{*}{ Population } & \multirow[b]{4}{*}{$\mathbf{N}$} & \multicolumn{3}{|c|}{ French CDI } & \multicolumn{2}{|c|}{ ASQ Communication domain } \\
\hline & & \multicolumn{2}{|c|}{ Lexicon size } & \multirow[b]{2}{*}{ Absence of word combination } & \multirow[b]{2}{*}{ Score } & \multirow[b]{2}{*}{ Below threshold } \\
\hline & & No. of words & $<10$ th percentile & & & \\
\hline & & $\overline{\text { Median [IQR] }}$ & $\%(n)$ & $\%(n / N)$ & Median [IQR] & $\%(n)$ \\
\hline \multicolumn{7}{|c|}{ Complete case analysis } \\
\hline Total population & 2424 & 48 [24-78] & $29.4(784)$ & $21.6(580 / 2393)$ & $48[28-55]$ & $20.5(572)$ \\
\hline $23-26$ weeks & 300 & $31[15-65]$ & $45.0(135)$ & $35.1(104 / 296)$ & $40[20-50]$ & $33.3(100)$ \\
\hline $27-31$ weeks & 1513 & $46[22-77]$ & $32.0(484)$ & $24.0(358 / 1492)$ & $45[30-55]$ & $23.9(362)$ \\
\hline \multirow[t]{4}{*}{ 32-34 weeks } & 611 & $51[27-80]$ & $27.0(165)$ & $19.5(118 / 605)$ & $50[30-55]$ & $18.0(110)$ \\
\hline & & & & nch CDI & ASQ Co & unication domain \\
\hline & & & Lexicon size & & & \\
\hline & & & $<10$ th percentile & Absence of word combination & \multicolumn{2}{|c|}{ Below threshold } \\
\hline Population & \multicolumn{2}{|r|}{$\mathbf{N}$} & Mean \% (95\% Cl) & Mean \% (95\% Cl) & \multicolumn{2}{|c|}{ Mean \% (95\% Cl) } \\
\hline \multicolumn{7}{|c|}{ After multiple imputation } \\
\hline Total population & & 3789 & $27.4(25.1-29.6)$ & $19.1(17.4-20.9)$ & \multicolumn{2}{|c|}{$18.6(16.8-20.4)$} \\
\hline 23-26 weeks & & 446 & $42.6(37.3-47.9)$ & $31.6(27.1-36.2)$ & \multicolumn{2}{|c|}{$30.6(25.9-35.3)$} \\
\hline $27-31$ weeks & & 2321 & $30.5(28.4-32.5)$ & $22.0(20.2-23.8)$ & \multicolumn{2}{|c|}{$22.2(20.3-24.1)$} \\
\hline 32-34 weeks & & 1022 & $25.0(21.9-28.2)$ & $17.1(14.6-19.5)$ & \multicolumn{2}{|c|}{$16.3(13.7-18.9)$} \\
\hline
\end{tabular}

Data for the total population are weighted to account for the different inclusion periods by gestational age.

Minimum and maximum are derived from the 36 sets of data generated.

English and in Italian in preterm children from various gestational age groups. ${ }^{17,18}$ Three measures were used to describe children's language acquisition: lexicon size, word combination use, and ASQ communication domain score. These measures are commonly used to define late language emergence at 24 months. ${ }^{19,20}$ We observed a strong association between these 3 measures. Other authors have stated that early expressive vocabulary acquisition may be a good measure of general language development in children with a very low birthweight. ${ }^{21}$ Compared with term children, children born at $<33$ weeks of gestation showed an increasing divergence in language abilities during the second year of life, which highlights the accuracy of assessing lexicon size at 2 years' corrected age. ${ }^{18}$ In our study, the rate of small lexicon

Table V. Association between lexicon size and ASQ domains for extremely, very and moderately preterm children

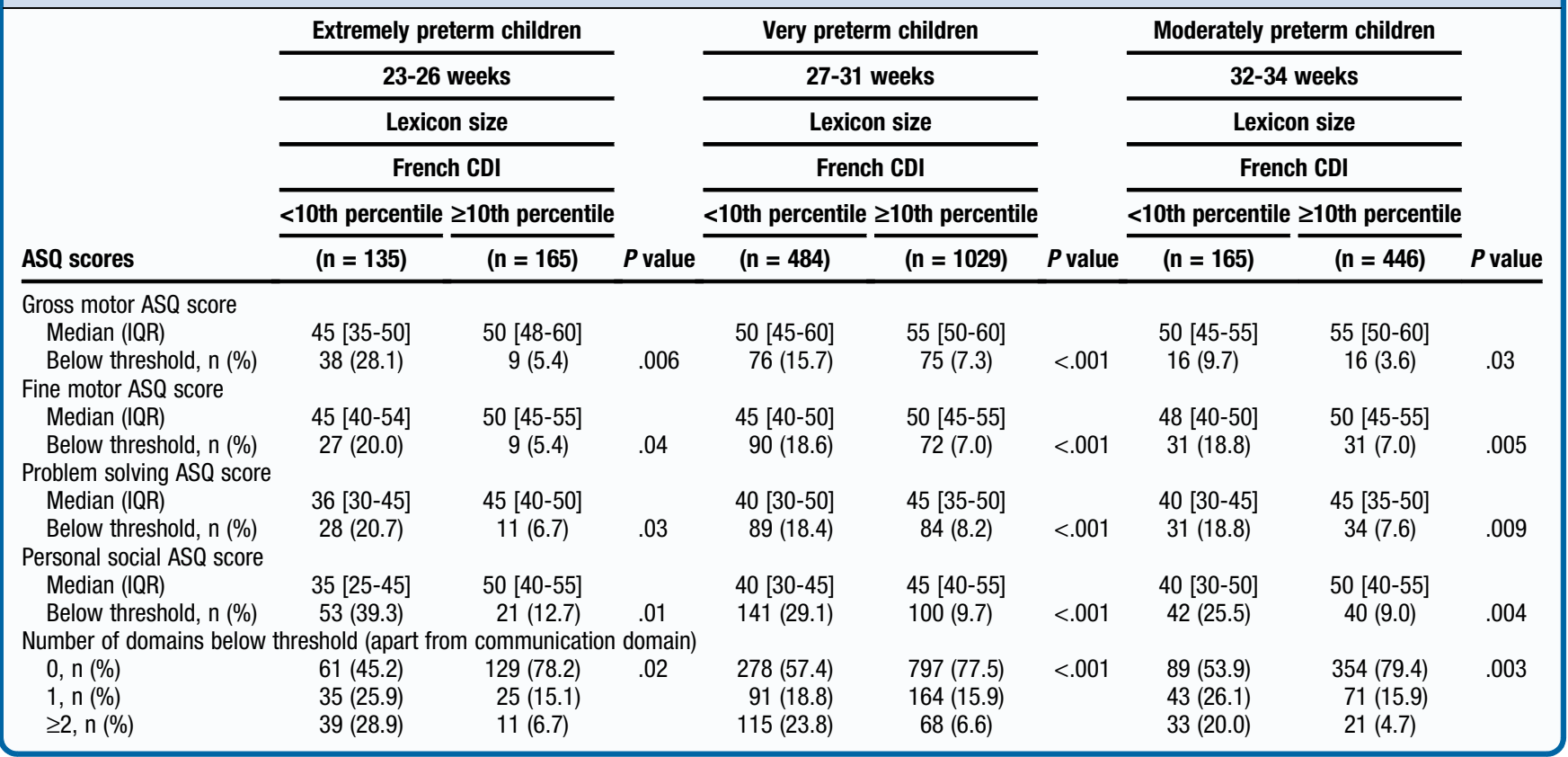

Random effect Gauss-Hermite models (20 quadrature points) to account for multiple births.

All unadjusted comparisons were statistically significant at $P<.001$.

$P$ is adjusted for gestational age (weeks), small for gestational age, sex, language spoken at home, maternal parity and maternal educational level

Thresholds for the ASQ domains scores: 38.07 for gross motor, 35.16 for fine motor, 29.78 for problem solving and 31.54 for personal social domains, respectively. 
size was greatest in extremely preterm children, but was also very high in very and moderately preterm children, 3 times higher than in the French test calibration. Results for use of word combination are of similar magnitude. Thus, language difficulties were not restricted to the most immature children.

One important finding in the current study is the association between small lexicon size and all other developmental functions. This association persisted after adjustment for potential confounders and was observed in all gestational age groups. We adjusted for gestational age and some other confounders, but not for neonatal morbidities because of their strong association with gestational age and their intermediate position on the causal pathway leading from low gestational age to poor neurodevelopment. ${ }^{22}$ Adams-Chapman et al found that extremely children with a low birthweight and a language delay at 30 months of corrected age had a significantly lower mental and psychomotor developmental index scores compared with children with no language delay. ${ }^{6}$ The association between poor language skills and poor skills in other developmental domains could have several explanations. Poor skills in some developmental domains could be an obstacle for the child to reach language developmental milestones. Indeed, the establishment of sensory and motor systems is one of the prerequisites for learning skills in infancy, such as language development. ${ }^{23}$ High-order networks used for language processing are built on more basic functions, such as hearing, which needs to be assessed in all children with language delay, or gestures. As an illustration, early communicative behaviors (gestures) are significantly correlated with motor skills at 12 months of corrected age in very preterm children. ${ }^{4}$ A common origin of difficulties in several developmental domains may also be suspected. Two complementary mechanisms could be involved together. The first one is based on cerebral structures; several studies have demonstrated associations between brain white matter abnormalities seen on magnetic resonance imaging and language abilities at ages 30 months, or 4 or 6 years. ${ }^{24,25}$ These white matter abnormalities could also lead to difficulties in other domains such as motor skills. The role of the cerebellum in nonmotor functions is also increasingly discussed. The cerebellum is a vulnerable structure in the preterm brain, and cerebellar injuries have functional consequences including neuromotor impairment, cognitive impairment, and disabilities, together with behavioral problems. ${ }^{26}$ Very few studies have examined the relation between cerebellar injuries and language development in preterm children; however, the cerebellum could be involved in both language and other developmental difficulties. Second, the kind of interactions and language exposure experienced by preterm children have been associated with language skills in very preterm children. ${ }^{27} \mathrm{~A}$ lack of adequate interactions from the hospital stay to the first months at home may be associated with the preterm birth and could be responsible for difficulties in several developmental domains. ${ }^{28}$ Term children with late language emergence (defined by an ASQ communication domain of $<-1 \mathrm{SD}$ ) are also more likely to be out of the normal range of the ASQ in all other domains, ${ }^{19}$ but this study did not adjust for potential confounders. Therefore, these associations among domains may not be specific to preterm children, but may be more easily seen in these vulnerable children.

The late consequences of a small lexicon size in preterm children need to be explored. In term children, a recent study focused on the risk of consequences in complex language skills, such as narrative skills and syntax complexity in children with late language emergence. ${ }^{20}$ Language abilities in very, moderate and late-preterm children have been reported to be stable from 20 months to 8 years of age, ${ }^{29}$ suggesting that language assessment at the end of the second year of life is predictive of later abilities. Our study shows that later assessments in preterm children with small lexicon size at 2 years of corrected age should not be limited to language skills.

This study has several strengths. The recruitment was population based, a large number of children were included, and a wide range of gestational age was studied. It has also some limitations, namely, the proportion of children lost to follow-up and the lack of formal developmental evaluation of the children. Only $64 \%$ of eligible children had complete follow-up data. Excluded children, as a group, accumulated factors that were associated with either better or poorer language skills, such as greater gestational age but lesser maternal educational level. The multiple imputation analysis conducted to take into consideration the children who were lost to follow-up did not significantly modify the results. No psychometric evaluations were conducted; only parental questionnaires were used. This approach made the study feasible despite the high number of children included and their geographical dispersion. The lack of formal evaluation is unlikely to impact the conclusions of the comparisons of development between groups with or without a small lexicon size.

Finally, the current study has 2 implications. First, it highlights the usefulness of assessing lexicon size at 2 years of corrected age in children born preterm. A small lexicon size can easily be identified using the short form of the CDI, even in preterm children with a routine follow-up. This finding may be especially useful for screening preterm children who do not have access to systematic, comprehensive follow-up with subspecialists. In most French regions, very preterm children benefit from a specialized follow-up after discharge, organized through perinatal networks, but some are lost to follow-up after a few months. Children born at 32-34 weeks of gestation usually have a routine follow-up by general practitioners or pediatricians only. Second, the strong association between language skills and performance in other developmental domains emphasizes that neurodevelopment must be viewed holistically during infancy. This finding should be considered when establishing preventive or remediation interventions in the preterm population. 
We are grateful for the participation of all families of preterm infants in the EPIPAGE-2 cohort study and for the cooperation of all maternity and neonatal units in France. We thank the EPIPAGE-2 Study Group for its substantial contribution to the conception, design, and acquisition of data and the revision of the manuscript (list of additional members of the EPIPAGE-2 Study Group is available at www.jpeds. com [Appendix]).

Submitted for publication Jul 1, 2018; last revision received Nov 10, 2018; accepted Dec 5, 2018.

Reprint requests: Marie-Laure Charkaluk, hôpital Saint-Vincent de Paul, service de néonatologie, BP 387, boulevard de Belfort, 59020 Lille cedex, France. E-mail: charkaluk.marie-laure@ghicl.net

\section{References}

1. Cheong JL, Doyle LW, Burnett AC, Lee KJ, Walsh JM, Potter CR, et al. Association between moderate and late preterm birth and neurodevelopment and social-emotional development at age 2 years. JAMA Pediatr 2017;171:e164805.

2. Barre N, Morgan A, Doyle LW, Anderson PJ. Language abilities in children who were very preterm and/or very low birth weight: a meta-analysis. J Pediatr 2011;158:766-74.

3. van Noort-van der Spek IL, Franken MC, Weisglas-Kuperus N. Language functions in preterm-born children: a systematic review and meta-analysis. Pediatrics 2012;106:1569-75.

4. Benassi E, Savini S, Iverson JM, Guarini A, Caselli MC, Alessandroni R, et al. Early communicative behaviors and their relationship to motor skills in extremely preterm infants. Res Dev Disabil 2016;48:132-44.

5. Sansavini A, Guarini A, Justice LM, Savini S, Broccoli S, Alessandroni R, et al. Does preterm birth increase a child's risk for language impairment? Early Hum Dev 2010;86:765-72.

6. Adams-Chapman I, Bann C, Carter SL, Stoll BJ , for the NICHD Neonatal Research Network. Language outcomes among ELBW infants in early childhood. Early Hum Dev 2015;91:373-9.

7. Stene-Larsen K, Brandlistuen RE, Lang AM, Landolt MA, Latal B, Vollrath ME. Communication impairments in early term and late preterm children: a prospective cohort following children to age 36 months. J Pediatr 2014;165:1123-8.

8. Ancel PY, Goffinet F, EPIPAGE 2 Writing Group. EPIPAGE 2: a preterm birth cohort in France in 2011. BMC Pediatr 2014;9(14):97.

9. Kern S, Langue J, Zesiger P, Bovet F. Adaptations françaises des versions courtes des inventaires du développement communicatif de MacArthur-Bates. ANAE 2010;107-108:217-28.

10. Squire J, Twombly E, Bricker D, Potter L. ASQ-3: user's guide. Baltimore (MD): Brookes Publishing; 2009.

11. Flamant C, Branger B, Nguyen The Tich S, de la Rochebroard E, Savagner C, Berlie I, et al. Parent-completed developmental screening in premature children: a valid tool for follow-up programs. PLoS One 2011;6:e20004.

12. Ego A, Prunet C, Blondel B, Kaminski M, Goffinet F, Zeitlin J. Customized and non-customized French intrauterine growth curves. II comparison with existing curves and benefits of customization. J Gynecol Obstet Biol Reprod 2016;45:165-76.
13. Sauzet O, Peacock J. Binomial outcomes in dataset with some clusters of size two: can the dependence of twins be accounted for? A simulation study comparing the reliability of statistical methods based on a dataset of preterm infants. BMC Med Res Methodol 2017;17:110.

14. Thorpe K. Twin children's language development. Early Hume Dev 2006;82:387-95.

15. Agarwal PK, Shi L, Daniel LM, Yang PH, Khoo PC, Quek BH, et al. Prospective evaluation of the Ages and Stages Questionnaire 3rd edition in very-low-birthweight infants. Dev Med Child Neurol 2017;59:625-30.

16. Beaulieu-Poulin C, Simard MN, Babakissa H, Lefebvre F, Luu TM. Validity of the language development survey in infants born preterm. Early Hum Dev 2016;98:11-6.

17. Marston L, Peacock JL, Calvert SA, Greenough A, Marlow N. Factors affecting vocabulary acquisition at age 2 in children born between 23 and 28 weeks' gestation. Dev Med Child Neurol 2007;49:591-6.

18. Sansavini A, Guarini A, Savini S, Broccoli S, Justice LM, Alessandroni R, et al. Longitudinal trajectories of gestural and linguistic abilities in very preterm infants in the second year of life. Neurospychologia 2011;49: 3677-88.

19. Zubrick SR, Taylor CL, Rice ML, Siegers DW. Late language emergence at 24 months: an epidemiological study of prevalence, predictors, and covariates. J Speech Lang Hear Res 2007;50:1562-92.

20. Domsch C, Richels C, Saldana M, Coleman C, Wimberly C, Maxwell L. Narrative skill and syntactic complexity in school-age children with and without late language emergence. Int J Lang Commun Disord 2012;47: 197-207.

21. Stolt S, Matomaki J, Lind A, Lapinleimu H, Haataia L, Lehtonen L. The prevalence and predictive value of weak language skills in children with very low birth weight - a longitudinal study. Acta Paediatr 2014;103:651-8.

22. Ancel PY, Goffinet F, , EPIPAGE-2 Writing Group Kuhn P, Langer B, Mathis J, et al. Survival and morbidity of preterm children born at 22 through 34 weeks' gestation in France in 2011: results of the EPIPAGE 2 cohort study. JAMA Pediatr 2015;169:130-8.

23. Maitre N. Neurorehabilitation after neonatal intensive care: evidence and challenges. Arch Dis Child Fetal Neonatal Ed 2015;100:F534-40.

24. Skiöld B, Vollmer H, Böhm B, Hallberg B, Horsch S, Mosskin M, et al. Neonatal magnetic resonance imaging and outcome at age 30 months in extremely preterm infants. J Pediatr 2012;160:559-66.

25. Woodward LJ, Clarck CA, Bora S, Inder TE. Neonatal white matter abnormalities: an important predictor of neurocognitive outcome for very preterm children. PLoS One 2012;7:e51879.

26. Brossard-Racine M, du Plessis AJ, Limperopoulos C. Developmental cerebellar cognitive affective syndrome in ex-preterm survivors following cerebellar injury. Cerebellum 2015;14:151-64.

27. Foster-Cohen SH, Friesen MD, Champion PR, Woodward LJ. High prevalence/low severity language delay in preschool children born very preterm. J Dev Behav Pediatr 2010;31:658-67.

28. Lowe JR, Erickson SJ, Maclean P, Schrader B, Fullier J. Association of maternal scaffolding to maternal education and cognition in toddlers born preterm and full term. Acta Paediatr 2013;102:72-7.

29. Putnick DL, Bornstein MH, Eryigit-Madzwamuse S, Wolke D. Long-term stability of language performance in very preterm, moderate-late preterm, and term children. J Pediatr 2017;181:74-9. 


\section{Appendix}

\section{Additional members of the EPIPAGE-2 Study Group}

Dominique Astruc, MD, University Hospital, Strasbourg, France

Pierre Kuhn, MD, PhD, University Hospital, Strasbourg, France

Bruno Langer, MD, University Hospital, Strasbourg,

France

Jacqueline Matis, MD, University Hospital, Strasbourg,

France

Carole Ramousset, MSc, University Hospital, Strasbourg,

France

Xavier Hernandorena, MD, La Côte Basque Hospital, Bayonne, France

Pierre Chabanier, MD, University Hospital, Bordeaux, France

Laurence Joly-Pedespan, MD, University Hospital,

Bordeaux, France

Marie-Joseph Costedoat, BSc, University Hospital,

Bordeaux, France

Annick Leguen, BSc, University Hospital, Bordeaux, France

Didier Lemery, MD, University Hospital Estaing,

Clermont-Ferrand, France

Bénédicte Lecomte, MD, University Hospital Estaing,

Clermont-Ferrand, France

Francoise Venditelli, MD, University Hospital Estaing,

Clermont-Ferrand, France

Gaël Beucher, MD, Department of Gynecology and

Obstetrics, University Hospital, Caen, France

Michel Dreyfus, MD, Department of Gynecology and

Obstetrics, University Hospital, Caen, France

Bernard Guillois, MD, Department of Neonatal Pediatrics

and Intensive Care, University Hospital, Caen, France

Yacine Tour, MSc, Department of Neonatal Pediatrics and

Intensive Care, University Hospital, Caen, France

Antoine Burguet, MD, PhD, Department of Neonatal

Pediatrics, University Hospital, Dijon, France

Pierre Sagot, MD, Department of Gynecology and

Obstetrics, University Hospital, Dijon, France

Noëlle Colas, BSc, Department of Gynecology and

Obstetrics, University Hospital, Dijon, France

Jacques Sizun, MD, University Hospital, Brest, France

Alain Beuche, MD, Department of Pediatrics, University

Hospital, Inserm-Irset U 1085, Rennes, France

Florence Rouget, MD, PhD, Department of Pediatrics,

University Hospital, Inserm-Irset U 1085, Rennes, France

Patrick Pladys, MD, PhD, Department of Pediatrics,

University Hospital, Rennes, France

Dominique Soupre, MD, Department of Pediatrics,

University Hospital, Vannes, France

Frédérique Charlot, CNM, Department of Pediatrics,

University Hospital, Inserm-Irset U 1085, Rennes, France

Sandrine Roudaut, CNM, University Hospital, Brest, France
Am,lie Favreau, MD, Department of Neonatal Pediatrics and Intensive Care, University Hospital, Tours, France

Elie Saliba, MD, PhD, INSERM U 930, Francois Rabelais University, Tours, France

Lucas Reboul, MSc, Department of Neonatal Pediatrics and Intensive Care, University Hospital, Tours, France

Nathalie Bednarek, MD, PhD, Department of Neonatal Pediatrics, University Hospital, Reims, France

Patrice Morville, MD, Department of Neonatal Pediatrics, University Hospital, Reims, France

Virginie Verrière, BSc, Department of Neonatal Pediatrics, University Hospital, Reims, France

Gérard Thiriez, MD, PhD, Department of Neonatal Pediatrics, University Hospital, Besançon, France

Christian Balamou, MD, Department of Neonatal Pediatrics, University Hospital, Besançon, France

Loïc Marpeau, MD, Department of Gynecology and Obstetrics, University Hospital, Rouen, France

Christiane Barbier, BSc, Department of Neonatal Pediatrics and Intensive Care, Rouen University HospitalLaboratory of microvascular endothelium and neonatal brain lesions, Rouen, France

Mayas El Ayoubi, MD, PhD, Department of Neonatal Pediatrics and Intensive Care, Cochin Hotel Dieu Hospital, Paris, France

Gilles Kayem, MD, PhD, Department of Obstetrics and Gynecology, Trousseau Hospital, Assistance Publique-Paris Hospitals (APHP), Paris, France - Inserm UMR1153, Perinatal and Pediatric Epidemiology Team, Paris, France

Xavier Durrmeyer, MD, PhD, Department of Neonatal Pediatrics and Intensive Care, CHI, CRC, Créteil, France - Inserm UMR1153, Perinatal and Pediatric Epidemiology Team, Paris, France

Michèle Granier, MD, Department of Neonatal Pediatrics, Sud Francilien Hospital, Evry, France

Olivier Baud, $\mathrm{MD}, \mathrm{PhD}$, Neonatal intensive care unit, Robert Debr, Hospital, INSERM, UMR 676, Paris, France

Bruno Carbone, MD, PhD, Department of Obstetrics and Gynecology, Trousseau Hospital, Assistance Publique-Paris Hospitals (APHP), Paris, France - Inserm UMR1153, Perinatal and Pediatric Epidemiology Team, Paris, France

Pierre-Henri Jarreau, MD, PhD, Department of Neonatal Pediatrics and Intensive Care, Cochin Hotel Dieu Hospital, Paris, France - Inserm UMR1153, Perinatal and Pediatric Epidemiology Team, Paris, France

Delphine Mitanchez, MD, PhD, Department of Neonatal Pediatrics, Trousseau Hospital, Paris, France

Pascal Boileau, MD, PhD, Department of Neonatal Pediatrics, Poissy Saint Germain University Hospital, Poissy, France

Laurence Foix L'Hélias, MD, PhD, Department of Neonatal Pediatrics, Trousseau Hospital, Paris, France Inserm UMR1153, Perinatal and Pediatric Epidemiology Team, Paris, France

Francois Goffinet, MD, PhD, Department of Gynecology and Obstetrics, Cochin Hotel Dieu Hospital, Paris, France; 
Inserm UMR1153, Perinatal and Pediatric Epidemiology Team, Paris, France

Laurie Cornu, MSc, Inserm UMR1153, Perinatal and Pediatric Epidemiology Team, Paris, France

Raphaëlle Moras, MSc, Inserm UMR1153, Perinatal and

Pediatric Epidemiology Team, Paris, France

Dienaba Sylla, MSc, Inserm UMR1153, Perinatal and

Pediatric Epidemiology Team, Paris, France

Pierre Boulot, MD, Department of Obstetrics and Gynecology, Arnaud de Villeneuve Hospital, Montpellier,

France

Gilles Cambonie, MD, PhD, Department of Neonatal

Pediatrics and Intensive Care, Arnaud de Villeneuve

Hospital, Montpellier, France

Hubert Daud, MD, CAMSP, University Hospital,

Montpellier, France

Renée-Pierre Dupuy, Reseau Grandir en Languedoc-

Roussillon, University Hospital, Nîmes, France

Antoine Bedu, MD, Department of neonatal pediatrics and intensive care, Limoges University Hospital, Limoges, France

Fabienne Mons, MD, Department of neonatal pediatrics and intensive care, Limoges University Hospital, Limoges, France

Claire Bahans, MSc, Department of neonatal pediatrics and intensive care, Limoges University Hospital, Limoges, France

Jeanne Fresson, MD, PhD, Department of Medical Information, Adolphe Pinard Maternity Unit, Nancy, France

J.M. Hascouet, MD, PhD, Adolphe Pinard Maternity Unit, Nancy, France

Rachel Vieux, MD, Department of Neonatal Pediatrics and Intensive Care, Adolphe Pinard Maternity Unit, Nancy, France

Lysiane Hilpert, BSc, Department of Medical Information, Adolphe Pinard Maternity Unit, Nancy, France

Catherine Alberge, MD, UMR 1027 INSERM,

Paul-Sabatier Toulouse III University, Toulouse, France

Catherine Arnaud, MD, PhD, UMR 1027 INSERM,

Paul-Sabatier Toulouse III University, Toulouse, France

Christophe Vayssière, MD, Department of Obstetrics and

Gynecology, Toulouse, France

Mireille Baron, CNM, UMR 1027 INSERM, Paul-Sabatier

Toulouse III University, Toulouse, France

Patrick Truffert, MD, PhD, CHU Lille, Department of Neonatal Pediatrics, F-59000 Lille, France

Damien Subtil, MD, PhD, Department of Gynecology and

Obstetrics, Jeanne de Flandre Hospital, Lille, France

Safirah Akowanou, MSc, CHU Lille, Department of Neonatal Pediatrics, F-59000 Lille, France

Claude D'Ercole, MD, PhD, Department of Gynecology and Obstetrics, Nord Hospital, Marseille, France

Umberto Simeoni, MD, PhD, Department of Neonatal Pediatrics and Intensive Care, La Conception Hospital, Marseille, France

André Bongain, MD, PhD, Department of Gynecology and Obstetrics, Archet Hospital, Nice, France
Bernard Branger, MD, Fédération des Réseaux de Sant, en Périnatalité, (FFRSP), Nantes, France

Norbert Winer, MD, PhD, Department of Gynecology and Obstetrics, Nantes, France

Jean-Christophe Rozé, MD, PhD, Department of Neonatal Medicine and INSERM CIC 004, Nantes, France

Valérie Rouger, $\mathrm{PhD}$, Department of Neonatal Medicine and INSERM CIC 004, Nantes, France

Claire Dupont, MSc, Department of Neonatal Medicine and INSERM CIC 004, Nantes, France

Jean Gondry, MD, Department of Obstetrics and gynecology, Amiens, France

André Léké, MD, PhD, Department of Pediatrics, Amiens

(PériTox UMI-01, Université de Picardie Jules Verne)

Gérard Krim, MD, PhD, Department of Neonatal

Pediatrics and Intensive Care, University Hospital, Amiens

France

Béatrice Baby, BSc, Department of Pediatrics, University

Hospital, Amiens France

Michel Deiber, MD, PhD, Department of Pediatrics, Chambéry, France

Olivier Claris, MD, PhD, Department of Neonatal Pediatrics and Intensive Care, University Hospital, Lyon, France

Jean-Charles Picaud, MD, PhD, Department of Neonatal Pediatrics and Intensive Care, La Croix Rousse Hospital, Lyon, France

Sophie Rubio-Gurung, MD, Reseau Perinatal Auror Ecl' aur, La Croix Rousse Hospital, Lyon, France

Catherine Cans, MD, PhD, University Joseph Fourier Grenoble 1 | UJF ú Pôle de Recherche - Chimie, Biologie, Santé, Grenoble France

Anne Ego, MD, PhD, INSERM CIC003, university Hospital, Grenoble, France

Thierry Debillon, MD, PhD, Department of Neonatal Pediatrics, University Hospital, Grenoble, France

Hugues Patural, MD, PhD, Neonatal intensive care unit, Nord Hospital, Saint-Etienne, France

Anne Rannaud, CNM, Department of Gynecology and Obstetrics, University Hospital, Grenoble, France

Anne Poulichet, MD, Department of Neonatology, University Hospital of Pointe à Pitre, French West Indies, Guadeloupe, Route de Chauvel BP 46597139 Les Abymes,

France

Eustase Janky, MD, PhD, Department of Obstetrics, University Hospital, Pointe à Pitre, Guadeloupe

Jean-Marc Rosenthal, MD, Department of Pediatrics,

University Hospital, Les Abymes, Guadeloupe

Eliane Colin, MSc, Department of Pediatrics, University Hospital, Les Abymes, Guadeloupe

Anne Favre, MD, Department of Neonatal Pediatrics and Intensive Care, Cayenne Hospital, Cayenne, Guyane, France Nicole Joly, BSc, Department of Neonatal Pediatrics and Intensive Care, Cayenne Hospital, Cayenne, Guyane, France Serge Châlons, MD, Department of Pediatrics, University Hospital, Fort de France, La Martinique, France

Véronique Lochelongue, BSc, Department of Pediatrics, University Hospital, Fort de France, La Martinique, France 
Pierre-Yves Robillard, MD, Department of Neonatal Pediatrics and Intensive Care, University Hospital Felix Guyon, Saint-Denis, La Réunion, France

Sylvain Samperiz, MD, Department of Neonatal Pediatrics and Intensive Care, University Hospital Felix Guyon, Saint-Denis, La Réunion, France

Duksha Ramful, MD, Department of Neonatal Pediatrics and Intensive Care, University Hospital Felix Guyon, Saint-Denis, La Réunion, France

Pierre-Yves Ancel, MD, PhD, Inserm UMR1153, Perinatal and Pediatric Epidemiology Team, Paris, France

Béatrice Blondel, PhD, Inserm UMR1153, Perinatal and Pediatric Epidemiology Team, Paris, France

Mercedes Bonet, MD, PhD, Inserm UMR1153, Perinatal and Pediatric Epidemiology Team, Paris, France

Anissa Brinis, PhD, Inserm UMR1153, Perinatal and Pediatric Epidemiology Team, Paris, France
Anaëlle Coquelin, MSc, Inserm UMR1153, Perinatal and Pediatric Epidemiology Team, Paris, France

Mélanie Durox, MSc, Inserm UMR1153, Perinatal and Pediatric Epidemiology Team, Paris, France

Babak Khoshnood, MD, PhD, Inserm UMR1153, Perinatal and Pediatric Epidemiology Team, Paris, France

Cécile Lebeaux, MD, Inserm UMR1153, Perinatal and Pediatric Epidemiology Team, Paris, France

Laetitia Marchand-Martin, MSc, Inserm UMR1153, Perinatal and Pediatric Epidemiology Team, Paris, France Marie-Josèphe Saurel-Cubizolles, PhD, Inserm UMR1153, Perinatal and Pediatric Epidemiology Team, Paris, France

Diep Tran, MSc, Inserm UMR1153, Perinatal and Pediatric Epidemiology Team, Paris, France

Loga Vasante-Annamale, MSc, Inserm UMR1153, Perinatal and Pediatric Epidemiology Team, Paris, France Jennifer Zeitlin, PhD, Inserm UMR1153, Perinatal and Pediatric Epidemiology Team, Paris, France 
Table I. Type of variable, model used to predict missing data, and percentages of values missing for each variable included in the imputation models ( 3789 children eligible for the study)

\begin{tabular}{lllc}
\hline Variable & \multicolumn{1}{c}{ Type of variable } & Model used to predict missing data & Percentage of values missing \\
\hline Gestational age & Categorical (11 categories) & Multinomial regression & No missing data \\
Small for gestational age & Binary & Logistic regression & No missing data \\
Sex & Binary & Logistic regression & No missing data \\
Primiparous & Binary & Logistic regression & 1 \\
Multiple pregnancy & Binary & Logistic regression & No missing data \\
Maternal educational level & Categorical (4 categories) & Multinomial regression & 2 \\
Parents' socioeconomic status & Categorical (6 categories) & Multinomial regression & 4 \\
Severe neonatal morbidity & Binary & Logistic regression & 11 \\
Breastfeeding at discharge & Categorical (3 categories) & Multinomial regression & 7 \\
Language spoken at home & Binary & Logistic regression & No missing data \\
French CDI & Binary & Logistic regression & 15 \\
Word combination & Categorical (3 categories) & Multinomial regression & 13 \\
ASQ communication score below threshold & Binary & Logistic regression & 11 \\
ASQ gross motor score below threshold & Binary & Logistic regression & 13 \\
ASQ fine motor score below threshold & Binary & Logistic regression & 14 \\
ASQ problem-solving score below threshold & Binary & Logistic regression & 15 \\
ASQ personal social score below threshold & Binary & Logistic regression & 14 \\
\hline
\end{tabular}

All imputation models include all variables in Table I.

Thresholds for the ASQ domain scores: 25.17 for communication, 38.07 for gross motor, 35.16 for fine motor, 29.78 for problem solving and 31.54 for personal social domains, respectively.

Table IV. Association between lexicon size, word combination and ASQ communication score

\begin{tabular}{|c|c|c|}
\hline \multirow[b]{3}{*}{ Word combinations and ASQ communication score in GA groups } & Lexicon size & Lexicon size \\
\hline & $>10$ th percentile & $<10$ th percentile \\
\hline & n (\%) & n (\%) \\
\hline Extremely preterm children (23-26 weeks) & 163 & 133 \\
\hline No word combination and ASQ communication below threshold & $5(3.1)$ & $72(54.1)$ \\
\hline No word combination and ASQ communication above threshold & $10(6.1)$ & 17 (12.8) \\
\hline Word combination and ASQ communication below threshold & $4(2.5)$ & 18 (13.5) \\
\hline Word combination and ASQ communication above threshold & $144(88.3)$ & $26(19.6)$ \\
\hline Very preterm children (27-31 weeks) & 1013 & 479 \\
\hline No word combination and ASQ communication below threshold & $17(1.7)$ & $250(52.2)$ \\
\hline No word combination and ASQ communication above threshold & $34(3.3)$ & 57 (11.9) \\
\hline Word combination and ASQ communication below threshold & $33(3.3)$ & $57(11.9)$ \\
\hline Word combination and ASQ communication above threshold & $929(91.7)$ & $115(24.0)$ \\
\hline Moderately preterm children (32-34 weeks) & 442 & 163 \\
\hline No word combination and ASQ communication below threshold & $5(1.1)$ & $75(46.0)$ \\
\hline No word combination and ASQ communication above threshold & $18(4.1)$ & 20 (12.3) \\
\hline Word combination and ASQ communication below threshold & $7(1.6)$ & 21 (12.9) \\
\hline Word combination and ASQ communication above threshold & 412 (93.2) & $47(28.8)$ \\
\hline Total (23-34 weeks) & 1618 & 775 \\
\hline No word combination and ASQ communication below threshold & $27(1.4)$ & $397(48.6)$ \\
\hline No word combination and ASQ communication above threshold & $62(3.9)$ & 94 (12.2) \\
\hline Word combination and ASQ communication below threshold & $44(2.1)$ & $96(12.6)$ \\
\hline Word combination and ASQ communication above threshold & $1485(92.6)$ & $188(26.6)$ \\
\hline
\end{tabular}

The threshold for the ASQ communication domain is 25.17 .

Percentages for "total" are weighted to account for the different inclusion periods by gestational age. 
Table VI. Association between lexicon size and ASQ domains for extremely, very and moderately preterm singleton children

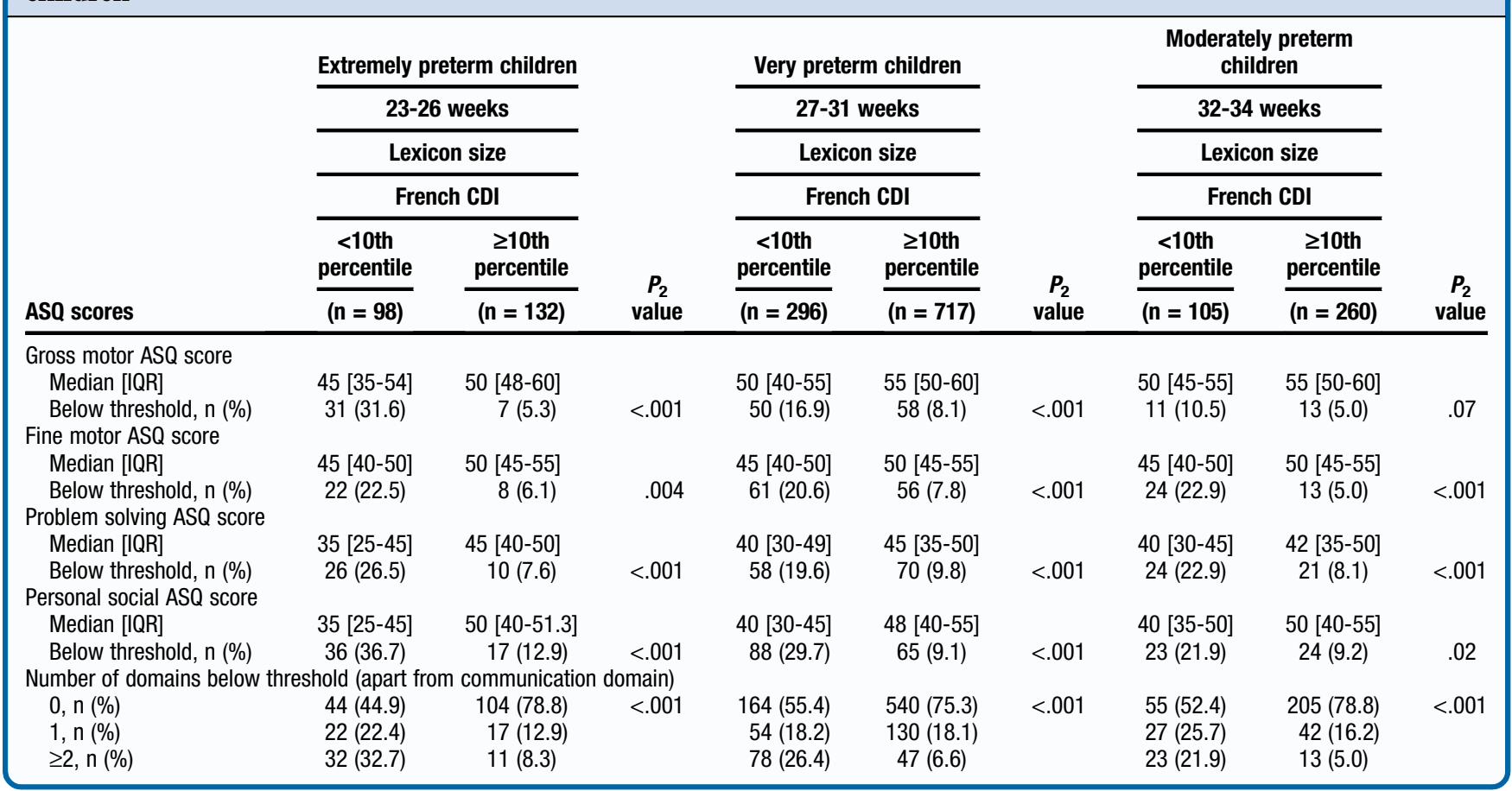

Logistic regression: $P$ is adjusted for gestational age (weeks), small for gestational age, sex, language spoken at home, maternal parity and maternal educational level. Thresholds for the ASQ domains scores: 38.07 for gross motor, 35.16 for fine motor, 29.78 for problem solving, and 31.54 for personal social domains, respectively. 